University of Nebraska - Lincoln

DigitalCommons@University of Nebraska - Lincoln

Publications from USDA-ARS / UNL Faculty

U.S. Department of Agriculture: Agricultural

Research Service, Lincoln, Nebraska

2001

\title{
Quantitative Trait Loci Associated with Milling and Baking Quality in a Soft X Hard Wheat Cross
}

\author{
Kimberley Garland Campbell \\ Washington State University, kim.garland-campbell@usda.gov \\ Patrick L. Finney \\ USDA-ARS
}

Christine J. Bergman

USDA-ARS

Daisy G. Gualberto

USDA-ARS

James A. Anderson

University of Minnesota

See next page for additional authors

Follow this and additional works at: https://digitalcommons.unl.edu/usdaarsfacpub

Part of the Agricultural Science Commons

Campbell, Kimberley Garland; Finney, Patrick L.; Bergman, Christine J.; Gualberto, Daisy G.; Anderson, James A.; Giroux, Michael J.; Siritunga, Dimuth; Zhu, Jiaqian; Gendre, Francois; Roué, Catherine; Vérel, Aliette; and Sorrells, Mark E., "Quantitative Trait Loci Associated with Milling and Baking Quality in a Soft X Hard Wheat Cross" (2001). Publications from USDA-ARS / UNL Faculty. 404.

https://digitalcommons.unl.edu/usdaarsfacpub/404

This Article is brought to you for free and open access by the U.S. Department of Agriculture: Agricultural Research Service, Lincoln, Nebraska at DigitalCommons@University of Nebraska - Lincoln. It has been accepted for inclusion in Publications from USDA-ARS / UNL Faculty by an authorized administrator of DigitalCommons@University of Nebraska - Lincoln. 
Authors

Kimberley Garland Campbell, Patrick L. Finney, Christine J. Bergman, Daisy G. Gualberto, James A.

Anderson, Michael J. Giroux, Dimuth Siritunga, Jiaqian Zhu, Francois Gendre, Catherine Roué, Aliette Vérel, and Mark E. Sorrells 


\title{
Quantitative Trait Loci Associated with Milling and Baking Quality in a Soft $\times$ Hard Wheat Cross
}

\author{
Kimberly Garland Campbell, Patrick L. Finney, Christine J. Bergman, Daisy G. Gualberto, \\ James A. Anderson, Michael J. Giroux, Dimuth Siritunga, Jiaqian Zhu, Francois Gendre, \\ Catherine Roué, Aliette Vérel, and Mark E. Sorrells
}

\begin{abstract}
Interclass hybridization between soft and hard wheat (Triticum aestivum $\mathbf{L}$.) results in new genetic combinations of potential value. We investigated whether interclass hybridization could improve enduse quality of both classes. Our objectives were to analyze quality traits in a population of recombinant inbred lines (RILs) derived from a cross between the good quality soft white wheat NY6432-18 (NY18), and good quality hard white wheat Clark's Cream (CC), identify quantitative trait loci (QTLs) for those traits, and use linkage analysis to determine which parent was contributing favorable alleles at specific QTLs for a given trait. The population was assessed for milling, protein and dough mixing, hydration, cookie and loaf traits. Traits were measured in two to six environments grown over three seasons in Ithaca, NY. The molecular map for the population contains $\mathbf{3 7 0}$ molecular markers including restiction fragment length polymorphisms (RFLPs), microsatellites, and markers derived from known function genes in wheat. Linkage groups have been located to all the wheat chromosomes except for 7D. Pinb derived from the puroindoline b gene on chromosome 5DS was the major QTL for milling, hydration, and cookie baking traits. The major QTL for mixograph peak time was at the $G l u-D y 1$ marker, derived from $G l u-D 1-2$ gene on chromosome 1DL. The Glu-AxI and Glu-By1 markers were QTLs for mixograph peak height and tolerance, respectively. QTLs for flour protein quantity were detected on chromosome $2 B$. With the exception of the hydration traits, multiple regression models included alleles from both parents. Interclass hybridization may be an underexploited wheat breeding strategy for improvement of agronomic and quality traits in wheat.
\end{abstract}

$\mathrm{F}_{\mathrm{t}}^{\mathrm{w}}$ EW WHEAT breeders routinely practice hybridizations among wheat classes because of the difficulty in recovering desired end-use quality characteristics.

K.G. Campbell, USDA-ARS Wheat Genetics, Quality, Physiology, \& Disease Research Unit, Washington State Univ., Pullman, WA 991646420; C. Bergman, USDA-ARS Rice Research Unit, Beaumont, TX, 77713; D. Gualberto and P.L. Finney, USDA-ARS Soft Wheat Quality Lab., Wooster OH, 44691; J. Anderson, Dep. of Agronomy and Plant Genetics, Univ. of Minnesota, St. Paul, MN 55116; M. Giroux, Dep. of Plant Sciences, Montana State Univ., Bozeman, MT 59715; D. Siritunga, Dep. of Plant Biology, The Ohio State Univ., Columbus OH 43210; J. Zhu and M. Sorrells, Dep. of Plant Breeding and Biometry, Cornell Univ., Ithaca, NY 14853; F. Gendre, C. Roué and A. Vérel, Danone Vitapole-15, Avenue Galileé, 92350 Le Plessis Robinson, FRANCE. Mention of trade names does not connote endorsement of products by The USDA-ARS, Cornell Univ., Montana State Univ., The Ohio State Univ. or The Univ. of Minnesota. Received 25 Jan. 2000. Corresponding author (kgcamp@wsu.edu).

Published in Crop Sci. 41:1275-1285 (2001).
Hybridization between soft and hard wheat creates new associations among loci. Advantages include an increase in genetic diversity, a potential increase in grain yield, and transfer of pest resistance genes. Both May et al. (1989) and Carver (1996) indicated that recovery of soft or hard wheat quality characteristics was possible in interclass single crosses if genetic variation for grain quality was maintained at a high level within the segregating population. A better understanding of the underlying genetic structure influencing wheat quality would hasten the development of unique wheats possessing value-added traits as well as wheats suited to conventional end-uses. Specifically, we wondered if interclass hybridization could create new associations among loci that would actually improve end-use quality of both hard and soft wheat.

Wheat flour is classified for use in baking on the basis of its texture (soft vs. hard) and chemical properties (primarily protein). In the USA, the main use of hard wheat flour is for bread baking and the main use of soft wheat flour is for cookie baking. Cookie flour is characterized by low water absorption, fine particlesize, and low protein content as compared with bread flour milled from hard wheat (Hoseney, 1988). During the initial milling step, soft wheat endosperm fractures through cell walls and hard wheat endosperm fractures at the cell wall. As a consequence, soft wheat flour particles are finer than those in hard wheat flours. Subsequent milling passes released intact starch granules in soft wheat flour. Starch wheat granules in hard wheat flour are fractured. The amount of damaged starch in flour is highly correlated with increased kernel hardness.

The amount of water required by bread dough, or the dough water absorption value, depends on damaged starch and protein content (Miller et al., 1997). The damaged starch is of value in yeast-leavened products because in addition to absorbing water, it acts as a substrate for $\alpha$-amylase and creates a favorable environment for yeast growth. In contrast, chemical-leavened soft wheat products have better texture if they are made from flour with small particle-size and low water reten-

Abbreviations: AWRC, alkaline water retention capacity; CC, Clark's Cream; HMW, high molecular weight; LMW, low molecular weight; NY18, NY 6432-18; QTL, quantitative trait locus; RIL, recombinant inbred line; LOD, likelihood of odds; RFLP, restriction fragment length polymorphism. 
tion capacity. Therefore damaged starch is undesirable in soft wheat flour (Bass, 1988).

The bread-baking potential of wheat is typically assessed on the basis of flour protein quantity, through the use of physical dough mixing and recording instruments such as the mixograph, and through experimental breadbaking procedures. An interrelationship between mixograph peak time, peak height, tolerance, and flour protein quantity exists. Good bread flours have strong gluten which is indicated by high protein quantity, long peak time, high peak height, and long or less negative tolerance values. A combination of short peak time, high peak height, and very negative tolerance is a characteristic of weak gluten flour. Weak gluten flours can also have short peak time, low peak height, and less negative tolerance. That type of flour could have good cookie baking qualities if it was soft with low protein quantity. Cookie baking potential is assessed based upon water absorption as measured by the alkaline water retention capacity (AWRC) test, which mimics the high $\mathrm{pH}$ environment of chemical leavened batters. AWRC has a strong negative correlation with cookie diameter (Yamazaki, 1953). Experimental cookie baking procedures are also used (Bloksma and Bushuk, 1988).

Flour yield from a small experimental mill is correlated with the straight grade flour yield from commercial mills. Higher flour yield is preferred for both hard and soft wheat. Softness equivalent is a measure of flour particle-size and is correlated to the yield of break flour from of commercial mills (Finney and Andrews, 1986). Break flour is released during the first pass of the wheat kernels through the mill break rolls. Wheats are either classified as hard or soft. Intermediate texture is not desired.

Specific genes with major effects on wheat end-use quality have been discovered. Kernel texture is controlled by a single locus $\mathrm{Ha}$ located on the short arm of chromosome 5D (Symes, 1965). Recently, Giroux and Morris (1998) reported that hard wheats do not have the puroindoline A (PINA) protein and do possess a glycine to serine mutation in the puroindoline B (PINB) protein. The loci for Pina and Pinb are tightly linked to each other on chromosome 5DS and probably function together as the $\mathrm{Ha}$ gene. Although texture is controlled primarily by a single locus, variation within soft and hard wheat classes has been reported (Hazen et al., 1997).

The glutenin and gliadin endosperm proteins have major effects on baking quality. The glutenin proteins are classified as low or high molecular weight based on the nature of their subunit composition. The low molecular weight (LMW) glutenin proteins are encoded by the Glu-3 orthologous genes on 1AS, 1BS, and 1DS. The high molecular weight (HMW) glutenin proteins are encoded by the Glu-1 orthologous genes on 1AL, 1BL, and 1DL. The gliadins are encoded by the Gli-1 and Gli-3 genes on 1AS, 1BS, and 1DS and the Gli-2 genes on 6AS, 6BS, and 6DS (Payne et al., 1984). Rousset et al. (1992) reported that allelic variation at three HMW glutenin loci accounted for part of the differences in flour protein content, dough water absorption, dough mixing time, bread loaf volume, and bread loaf crumb score among a set of recombinant inbred hard spring wheat lines. The combined additive effects of the HMW glutenin loci accounted for an average of just $13 \%$ of the parental differences in bread-baking quality, indicating that other loci were involved. For example, Prasad et al. (1999) recently identified a QTL on 2DL that explained $18 \%$ of the variation in grain protein content in a cross between two Indian wheat cultivars. A chromosome segment on 6BS in Triticum turgidum L. subsp. dicoccoides increased protein quantity (Joppa et al., 1997). That chromosome segment was subsequently transferred and mapped in hexaploid wheat (Khan et al., 2000). Law et al. (1978) noted that 5DL influenced grain protein content in 'Chinese Spring'/'Hope' chromosome substitution lines. Quantiative trait loci for grain protein content have been identified on 4B, 5A, 6A, 6B, and 7B in durum wheat (Blanco et al., 1996).

Wheat genetic stocks have been used to locate wheat quality loci to chromosome arms. Mansur et al. (1990) reported that dough water absorption was increased by 'Cheyenne' chromosomes $1 \mathrm{~A}, 1 \mathrm{~B}, 1 \mathrm{D}, 2 \mathrm{D}$, and $3 \mathrm{~B}$ in a study of recombinant chromosome substitution lines of the hard wheat Cheyenne into a Chinese Spring background. Loaf volume was increased by Cheyenne chromosomes 1A, 1B, 1D, 3A, 3B, 7A, and 7B. Mixing time was increased by chromosomes $1 \mathrm{D}$ and $7 \mathrm{~A}$. Flour protein content was increased by Cheyenne chromosomes $1 \mathrm{~A}, 4 \mathrm{~A}$, and $5 \mathrm{D}$, and decreased by chromosomes $1 \mathrm{~B}$, 2A, 6B, and 7B. Zemetra et al. (1987) studied flour mixing time and mixing tolerance (a measure of a dough's ability to resist breakdown) in a set of reciprocal substitution lines between the hard wheat cultivars Wichita and Cheyenne. Significant effects on flour mixing time were noted for chromosome $1 \mathrm{~B}$ and 2D. Chromosome $1 \mathrm{~B}$ also influenced mixing tolerance as did $3 \mathrm{~B}$ and $7 \mathrm{~B}$.

Previous studies investigated the genetic control of milling and baking traits in crosses between good and poor quality hard wheat cultivars or between a good quality hard wheat cultivar and a poor quality soft wheat cultivar like Chinese Spring. Bergman et al. (1998) reported heritabilities and genetic correlations for quality traits among a set of RILs derived from a soft (NY18) by hard (CC) white wheat cross. They noted that transgressive segregation occurred among RILs for most quality traits indicating that alleles from both parents influenced end-use quality. The soft wheat parent NY18 has high flour yield and good baking characteristics for the cookies and cakes typically made from soft wheat flour. The hard wheat parent, CC, produces flour with good bread-baking characteristics. The population was used to determine QTL associated with resistance to pre-harvest sprouting (Anderson et al., 1993). The same population was used to determine QTL associated with kernel traits and flour viscosity (Campbell et al., 1999; Udall et al., 1999).

Our objectives were to analyze quality traits in a cross between good quality soft and hard wheat, identify QTLs for those traits, and use linkage analysis to deter- 
mine which parent was contributing favorable alleles at specific QTLs for a given trait.

\section{MATERIALS AND METHODS}

The population consisted of $78 \mathrm{~F}_{2: 5}$ derived RILs from the NY18/CC cross. The RILs were grown in two locations near Ithaca, NY, from 1992-1994 for a total of six environments. The experiments were grown at the Caldwell and Ketola research farms in 1992 (Environments 1 and 2), at the Caldwell and Snyder research farms in 1993 (Environments 3 and 4), and at the Caldwell and McGowen research farms in 1994 (Environments 5 and 6). Population development, growing procedures and sample preparation for quality analyses have been described previously (Campbell et al., 1999).

\section{Trait Analyses}

Grain samples were tempered to $140 \mathrm{~g} \mathrm{~kg}^{-1}$ moisture and $450 \mathrm{~g}$ (25g in 1992) were milled on a Brabender Quadrumat Jr. Laboratory mill (Brabender Co., Hackensack, NJ) according to Finney and Andrews (1986). The mill had been preheated to prevent expansion of the rolls during operation. The ground wheat was transferred to a 25.4-cm Great Western sifter (Great Western Mfg. Co., Leavenworth, KS) consisting of a 54-mesh (368-um) screen and a 94-mesh (180 um) screen and sieved for $1.5 \mathrm{~min}$. Flour yield was calculated by the following formula:

$$
\begin{aligned}
\text { Flour Yield }= & \{[450 \mathrm{~g}-(x \mathrm{~g} \text { on } 54 \text { mesh })] \\
& / 450 \mathrm{~g}\} \times 100 .
\end{aligned}
$$

where $x$ is the mass of flour on the mesh screen.

Softness equivalent was calculated as the percentage of flour that passed through the 94-mesh sieve:

$$
\begin{aligned}
\text { Soft. Eq. }= & \{450 \mathrm{~g}-[(x \mathrm{~g} \text { on } 54 \text { mesh }) \\
& -(x \mathrm{~g} \text { on } 94 \text { mesh })]\} /[450 \mathrm{~g} \\
& -(x \mathrm{~g} \text { on } 54 \text { mesh })] \times 100
\end{aligned}
$$

where $x$ is the mass of flour on the mesh screen.

Flour Yield and softness equivalent were calculated similarly in 1992 except that $25 \mathrm{~g}$ replaced $450 \mathrm{~g}$ in Eq. [1] and [2]. Flour protein quantity was measured on grain samples from two replications per each of the six environments by near infrared reflectance [American Association of Cereal Chemistry (AACC) method 39-11] calibrated to standards determined by the Kjeldahl procedure (AACC method 46-12). The reference for all AACC methods is AACC, 1983. Protein was expressed on a $14 \mathrm{~g} \mathrm{~kg}^{-1}$ moisture basis. AWRC was determined according to Yamazaki et al. (1968). Damaged starch was measured on flour samples from two replications in environments 5 and 6 by means of fungal $\alpha$-amylase (Enzeco Development Corporation, New York, NY) (AACC method 76-30A).

Dough mixing properties were measured on flour samples from two replications in four environments $(3,4,5$, and 6) with a mixograph (National Manufacturing Division, TMCO, Lincoln, NE) capable of analyzing 2-g samples. Instrument set up was as described in Bergman et al. (1998). In this study, we analyzed the following parameters from the mixograph curve for each sample: peak time-time in minutes until dough reached maximum resistance; peak height — the percent torque at peak time; and tolerance-the slope of the curve midline from peak time until 1 min after peak time. The slope to the right of the peak is a measure of dough breakdown (mixing tolerance) as indicated by a decrease in resistance. Tolerance was a negative number.

Baking tests were conducted on the samples from the 1994 environments only. Flour from each of two replications per location was bulked by genotype to obtain enough flour for baking. Bread mixing time, dough water absorption, loaf volume, and crumb grain were assessed as in Shogren and Finney (1984). Sugar snap cookie diameter and top grain were determined according to the AACC method 10-52.

\section{Analysis of Quantitative Trait Loci}

Procedures for developing the molecular marker linkage map for the NY18/CC population and for determining descriptive statistics, tests of normality, and homogeneity of variance across locations were described previously (Bergman et al., 1998; Campbell et al., 1999). The current molecular map for this population comprises 370 markers in 52 linkage groups of two or more markers; 49 markers remain unlinked. In Campbell et al. (1999), the map was described as having 301 markers. Since that time several markers were rescored and either corrected or deleted. Several new markers were added to the dataset including RFLP clones from the Colorado State University, Iowa State University, and University of Arizona libraries. Additional markers derived from coding genes included the barley alchohol dehydrogenase $A d h 3$ (Trick, et al., 1988), an abscisic acid responsive protein kinase Pkabal (Gomez-Cadenas, et al., 1999) and a potassium transporter Hkt1 (Schachtman and Schroeder, 1994).

Linkage groups were assigned to chromosomes on the basis of homology with existing wheat maps. When more than one linkage group was assigned to the same chromosome, numbers were assigned (beginning from 1) to distinguish them. The linkage groups are distributed throughout the wheat genome with the best coverage on homoeologous chromosome groups 1 and 2. At least one linkage group has been placed upon each wheat chromosome except 7D.

A logarithmic transformation was applied to the data for mixograph peak time and for bread mixing time normalize the distribution of those traits. For all traits, the nature of significant genotype $\times$ environment interactions was examined by determining the ranks of genotype values within locations and rank correlation was used to compare genotype ranks across locations. Heritability for all traits was calculated on a generation means basis (Knapp et al., 1985).

The locations of QTLs were determined through one-way analysis of variance within environments and upon mean trait values for each RIL over environments by the mapping software Map Manager QT (Manly and Olson, 1999). We defined a QTL as a marker that had a significant [likelihood of odds (LOD) score $>2$ ] association with the mean trait value (Table 1). Although this somewhat lenient definition of a QTL resulted in a high probability of type 1 error (identifying a QTL where one did not exist), we opted to control type 2 error instead and confirm our results in other populations and future generations of this population.

Highly significant QTLs not linked to other potential QTLs inflate the total genetic variation and make it difficult to discover additional loci influencing a trait. The Pinb locus was highly significant for flour yield, softness equivalent, damaged starch, AWRC, and cookie diameter. Therefore we also analyzed each marker-trait combination for those traits in a multiple regression model that included Pinb (control for QTL at Pinb ). The procedure is similar to composite interval mapping (Zeng, 1993). We did not perform interval mapping because the Pinb locus was not linked to other markers in our map.

Graphical genotypes (Fig. 2) were constructed to compare markers across traits. A marker-trait association was included on that figure if it was significant at $P<0.01$. The results from the analyses with control for QTL at Pinb are also included on that figure for comparative purposes. 
Table 1. The most significant QTLs† for milling and baking quality traits.

\begin{tabular}{|c|c|c|c|c|c|}
\hline Trait & Chromosome & Marker & $\begin{array}{c}\text { LOD score } \\
\text { for trait mean }\end{array}$ & $\begin{array}{c}R^{2} \text { for } \\
\text { trait mean }\end{array}$ & $\begin{array}{c}R^{2} \text { for trait within } \\
\text { environments } \ddagger\end{array}$ \\
\hline \multicolumn{6}{|l|}{ Milling traits } \\
\hline \multirow[t]{2}{*}{ Flour yield } & 3S-1 & ksuG53 & 2.3 & 12 & $10,11,9,9,14,6$ \\
\hline & 5DS:5AS,5BS,5DS§ & Pinb & 10.9 & 48 & $\mathbf{3 8 , 1 4 , 3 5 , 4 3 , 5 3 , 4 3}$ \\
\hline Softness equivalent & 5DS:5AS,5BS,5DS & Pinb & 13.8 & 57 & $\mathbf{5 1}, \mathbf{3 6 , 5 1 , 5 7 , 5 4 , 5 7}$ \\
\hline \multicolumn{6}{|l|}{ Mixing traits } \\
\hline \multirow[t]{5}{*}{ Flour protein } & 1A-1 & $a b c 156 b$ & 3.0 & 15 & $13,0,9,14,6,13$ \\
\hline & 2B-1 & $c d o 1445 b$ & 5.2 & 24 & $1,0,9,27,18,23$ \\
\hline & 2B-2 & bcd1688a & 4.5 & 22 & $0,0,7,28,16,22$ \\
\hline & 2B-2 & bcd1307a & 4.0 & 20 & $0,0,7,24,14,22$ \\
\hline & 7AL:7AL,7BL,7DL & $k s u G 12 b$ & 2.7 & 13 & $11,9,11,7,9,10$ \\
\hline \multirow[t]{2}{*}{ Mixograph peak time } & 1DL & Glu-Dy1 & 8.7 & 39 & $\mathbf{3 9}, \mathbf{3 1}, \mathbf{4 0}, \mathbf{3 3}$ \\
\hline & 4AL:4AL,7AS,7DS-1 & ksuERI & 2.2 & 11 & $10,11,10,9$ \\
\hline \multirow[t]{2}{*}{ Bread mixing time } & 1B & ksuF43c,e & 2.6 & 13 & 11,14 \\
\hline & 1DL & Glu-Dy1 & 7.4 & 35 & 41,29 \\
\hline \multirow{3}{*}{ Mixograph peak height } & 1AL-1 & GluAx1 & 2.9 & 15 & $16,11,8,7$ \\
\hline & 1AL-2 & bcd592a & 3.1 & 16 & $17,13,7,8$ \\
\hline & 1BL-1 & Glu-By1 & 2.7 & 14 & $13,9,13,15$ \\
\hline \multirow[t]{3}{*}{ Mixograph tolerance } & 1A-1 & mwg938a & 2.8 & 14 & $11,0,18,11$ \\
\hline & 1AL-2 & mwg695Hda & 2.4 & 12 & $13,5,1,2$ \\
\hline & 1BL-1 & Glu-By1 & 3.6 & 18 & $17,8,2,1$ \\
\hline \multicolumn{6}{|l|}{ Hydration traits } \\
\hline \multirow[t]{2}{*}{ Dough water absorption } & 3L-1 & mwg69 & 2.1 & 13 & 11,9 \\
\hline & 5DS:5AS,5BS,5DS & Pinb & 3.5 & 18 & 22,8 \\
\hline \multirow{2}{*}{ Damaged starch } & 4DL:4BL,4DL,5AL-2 & bcd1431b & 2.0 & 10 & 9,10 \\
\hline & 5DS:5AS,5BS,5DS & Pinb & 15.5 & 61 & 60,62 \\
\hline \multirow[t]{2}{*}{ AWRC } & 4DL:4BL,4DL,5AL-2 & bcd1431b & 2.2 & 12 & $13,2,8,5,10,12$ \\
\hline \multirow{2}{*}{\multicolumn{6}{|c|}{ Baked product traits }} \\
\hline & & & & & \\
\hline \multirow{5}{*}{$\begin{array}{l}\text { Cookie diameter } \\
\text { Cookie top grain }\end{array}$} & 5DS:5AS,5BS,5DS & Pinb & 8.2 & 40 & 35,38 \\
\hline & 3B & cdo718 & 2.2 & 11 & 8,4 \\
\hline & 5BL:5AL,5BL,5DL-1 & cdo412 & 3.7 & 19 & 13,9 \\
\hline & 5DS:5AS,5BS,5DS & Pinb & 3.6 & 20 & 39,0 \\
\hline & 5 & wms111a & 2.2 & 12 & 12,6 \\
\hline \multirow[t]{4}{*}{ Loaf volume } & 2B-1 & Pkabalc & 2.3 & 12 & 11,9 \\
\hline & 2B-2 & $r z 753 R V$ & 2.0 & 10 & 7,11 \\
\hline & $5 \mathbf{L}$ & bcd873b & 2.1 & 11 & 13,5 \\
\hline & 7AL:7AL,7BL,7DL & $w g 466$ & 2.2 & 11 & 9,8 \\
\hline Crumb grainfI & 4DL:4BL,4DL,5AL-1 & bcd402 & 1.8 & 9 & 11,1 \\
\hline
\end{tabular}

$\dagger$ A QTL was included in this table if it was associated with the trait with a LOD score $\geq 2$.

$\$$ Environments are listed in order from 1 through 6 for traits measured in all six environments, from 3 through 6 for traits measured in four environments and from 5 through 6 for traits measured in two environments.

$\S$ Markers on chromosomes 4, 5, and 7 are listed with their chromosome homologies according to Nelson et al. (1995).

Il $b c d 402$ was the most significant marker for Crumb Grain although not at LOD $>2$.

We also detected significant markers and interactions between them using multiple regression for each trait mean to include significant markers and interactions as:

$$
\begin{aligned}
m Y_{j}= & b_{0}+b_{1} X_{i 1}+b_{2} X_{i 2}+b_{3}\left(X_{i 1}\right)\left(X_{i 2}\right) \ldots \\
& +b_{p-1} \mathrm{X}_{i, p-1}+e_{i} .
\end{aligned}
$$

In the model, $X_{i l}, X_{i 2}, \ldots, X_{i, p-1}$ denote alleles of the RIL at the $i$ th locus with $p-1$ markers and $m Y_{j}$ denotes a trait mean over locations. Markers were selected for multiple regression models so that (i) the proportion of phenotypic variation explained by the markers was maximized, (ii) the number of RILs included in the model was maximized, and (iii) the total number of markers in the model was minimized. Markers were added to the model if their partial regression coefficients were significantly different from zero at $P<0.05$. Multiple regression models were constructed by QGENE (Nelson, 1997).

\section{RESULTS}

The traits were normally distributed except for softness equivalent and damaged starch (Fig. 1). Those traits were bimodal, supporting previous research indicating that endosperm texture is controlled largely by one locus. In Environments 5 and 6, AWRC was also bimodal. The distributions for mixograph peak time and bread mixing time were both skewed to the left. In both cases, a logarithmic transformation improved the normality of the distribution.

The hard wheat CC parental checks had higher values for the traits associated with bread baking and hydration: flour protein, mixograph peak time, bread mixing time, mixograph peak height, dough water absorption, damaged starch, AWRC, and loaf volume. The soft wheat NY18 parental checks had higher values for softness equivalent, cookie diameter, and crumb grain. The two parents possessed similar values for flour yield and mixograph tolerance. The maximum and minimum trait values among the RILs significantly exceeded parental values for all traits except cookie top grain indicating that most traits were improved by alleles from both parents.

In a combined analysis of variance for each trait across environments, all effects (environment, genotype, and their interactions) were highly significant $(P<0.01$, data not shown). Environments were considered fixed and genotypes random in those analyses. Differences among environments were the single largest source of variation for all traits. The 1992 harvest season (Environments 1 and 2) was delayed because of rain at harvest and some preharvest sprouting occurred. Grain fill and harvest conditions for all other environments 
were good. Samples from Environments 1 and 2 were harder, with lower protein and test weights than other environments. Flour yield and AWRC were higher in Environments 1 and 2, and the range in genotype values was narrower. For most of the traits, the range in genotype values was greater in Environments 5 and 6 than in other environments. A larger range in genotype values facilitates QTL detection.

The nature of the significant genotype $\times$ environment interactions was further examined through rank correlation. Detection of consistent QTLs across environments occurs only if genotype ranks for a given trait are similar from one environment to another. The rank correlations for genotype means among environments 3,4,5, and 6 were significant and high $(R>0.6)$ for all traits except cookie top grain, mixing tolerance, and bread crumb grain. Correlations of genotype ranks involving Environment 2 were lower than those involving other environments, most notably for flour protein $(R<0.30)$. Lack of correlation among genotype ranks from one environment to another could be due to unique environmental influences affecting a particular trait in a particular environment, or they could be because of error in our estimation of the genotype value in a particular environment. Flour protein values were lower in Environments 1 and 2 than in other environments because of harvest conditions. Both mixing tolerance and bread crumb grain were measured with a high degree of experimental error (data not shown). The results of the rank correlations indicated that environment-specific associations between markers and trait values were likely for flour protein, mixing tolerance, cookie top grain and bread crumb grain.

\section{Quantitative Trait Loci: Milling Traits}

\section{Flour Yield and Softness Equivalent}

Pinb had a strong influence on the milling traits in all six environments (Table 1 ) and it was the only marker that was significant for both milling traits (Fig. 2). The soft parent, NY18, possessed the wild-type allele at Pinb. Clark's Cream possessed the glycine to serine mutation. The significant association between flour yield and loci on 1B, 1BL-2, 3B, 3S-1, and 6B was detected with or without Pinb in the model. When the analysis was controlled for the effects of Pinb, significant loci were observed for flour yield on 3A and 4AL-1. Similarly, significant loci for softness equivalent were observed on 1A-2, and 2A when Pinb was in the model (Fig. 2). For both milling traits, the best multiple regression model included alleles from both parents (Table 2 ). The best multiple regression model for increased softness equivalent included a marker, $k s u H 7 b$, that was significant for flour yield and cookie diameter when we analyzed marker-trait associations independently, but not for softness equivalent.

\section{Quantitative Trait Loci: Dough Mixing Traits}

Flour Protein, Mixograph Peak Time, Bread Mixing Time, Mixograph Peak Height, Mixograph Tolerance

The primary QTLs for flour protein quantity were on 2B-2. Those QTLs were not detected in Environment
2 (Table 1). Although CC consistently possessed 1\% higher protein than NY18 in all environments, the NY18 alleles on 1A-1, 1A-2, 2B-2, 5AL, and 7AL increased flour protein (Fig. 2). The best multiple regression model for increased flour protein included markers on 2B, 3L, 5AL, and 5DL. In the multiple regression model, alleles for increased flour protein were contributed by both parents (Table 2).

The HMW glutenins had a major effect on mixograph traits. CC possessed alleles encoding HMW glutenin subunits as follows: 2 at Glu-A1; 7 and 8 at Glu-B1; 5 and 10 at Glu-D1. NY18 possessed subunits: 1 at Glu$A 1 ; 7$ and 9 at Glu-B1; 2 and 12 at Glu-D1. Although the Glu-D1-1 and Glu-D1-2 loci are tightly linked; recombination had occurred in three RILs.

A major QTL for mixograph peak time and bread mixing time was located at the Glu-Dy1 marker. Markers derived from glutenin genes on 1AL-1 and 1BL-1 were not associated with peak or mixing time. NY18 alleles resulted in increased peak and mixing time on chromosome $1 \mathrm{~B}$ and $3 \mathrm{~S}-2$. The multiple regression models were identical for increased mixograph peak time and bread mixing time but different from that for flour protein. Both parents contributed alleles for higher values.

The major QTLs for mixograph peak height were at the HMW glutenin loci on 1AL-1 and 1BL-1 (Table 1). The NY18 allele at Glu-AxI and the CC allele at GluBy1 increased peak height. Loci associated with peak height were not associated with peak time (Fig. 2). The multiple regression model for peak height included a locus, $b c d 1307 a$, that was a highly significant QTL for flour protein (Tables $1 \& 2$ ). Both parents contributed alleles for higher values at peak height.

$G l u-B y 1$ was also a QTL for mixograph tolerance. On 1AL-2 and 1BL-1, peak height and mixograph tolerance were increased by alleles from opposite parents. NY18 always contributed the allele for higher (longer and more positive) mixograph tolerance except at ksuG53a on 3AS-1 (Fig. 2). QTLs for mixograph tolerance were inconsistent across environments with the exception of marker $m w g 938 a$ on $1 \mathrm{~A}-1$.

\section{Quantitative Trait Loci: Hydration Traits}

\section{Dough Water Absorption, AWRC, Damaged Starch}

The bimodal distributions observed for AWRC and damaged starch in Environments 5 and 6 indicated that a single major gene was controlling the trait in those environments. We assume that $\mathrm{Ha}$ is that gene. The strongest QTL for hydration traits was at Pinb on 5DS. The LOD score for the effect of Pinb on damaged starch, 15.5, was the highest noted for any trait in this population. Dough water absorption was increased by the $\mathrm{CC}$ alleles on 1DL, 2A, 2B-1, 2DL-1, 3L-1, 5DS and 7AS. It was increased by the NY18 allele on $2 \mathrm{~B}-2$ and $3 \mathrm{~S}$ 2 after the influence of Pinb was taken into account (Fig. 2).

A QTL for both damaged starch and AWRC was found at $b c d 1431 b$ on 4DL-2. Those two traits frequently shared significant markers. Softness equivalent and hydration traits shared significant markers on 1A-2, 


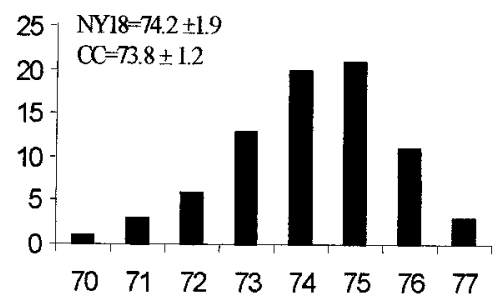

Adjusted Flour Yield (\%)

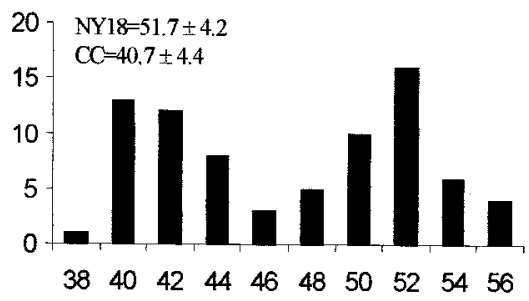

Softness Equivalent (\%)

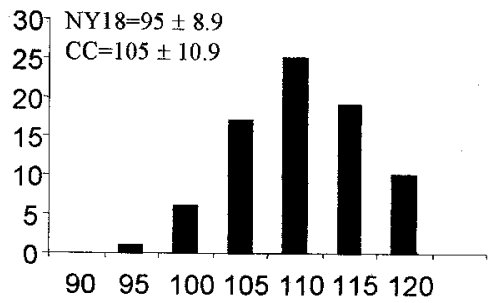

Flour Protein (g kg-1)

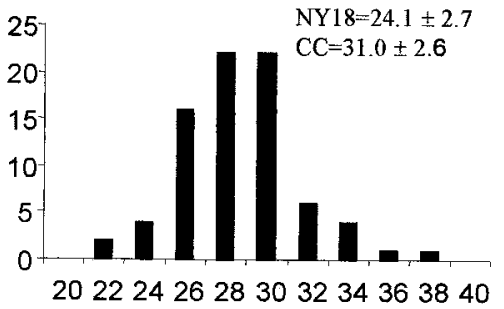

Mixograph Peak Height ( $\mathrm{mm}$ )
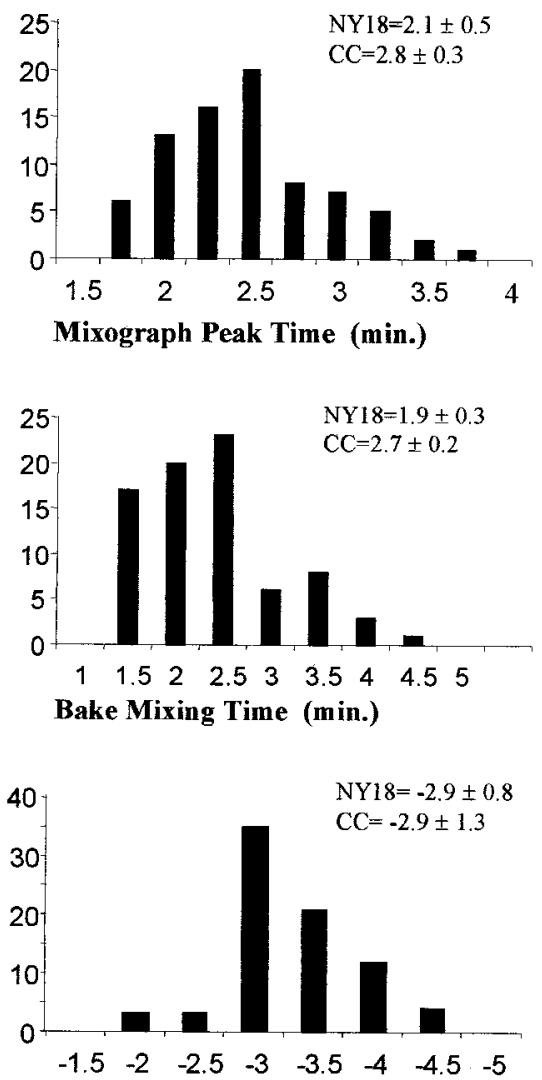

Mixograph Tolerance $-(\mathrm{mm} / \mathbf{m i n})$

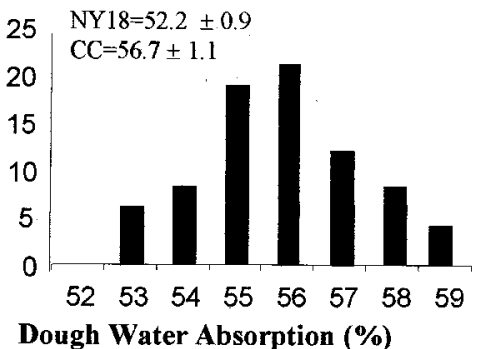

Fig. 1. Histograms of phenotypic means for milling and baking quality traits. The $y$-axis in all graphs is the number of recombinanat inbred lines(RIL). AWRC denotes the alkaline water retention capacity.

2A, 2DL-1, 4DL-2, and 5DS. Parental alleles influenced softness equivalent and hydration traits in opposite directions, probably due to the effect of kernel hardness on starch damage. In contrast, when flour yield and hydration traits shared markers, (on 5DS, and 6B) the parental alleles influenced the traits in the same direction.

\section{Quantitative Trait Loci: Baked Products}

\section{Cookie Diameter, Top Grain, Loaf Volume,}

\section{Crumb Grain}

Quantitative trait loci for cookie traits were different from those for bread in most cases. The QTL at Pinb was a major influence on cookie diameter and top grain. The CC allele at Pinb increased flour yield, dough water absorption, damaged starch and cookie top grain. The NY18 allele increased softness equivalent and cookie diameter. Whenever a locus was associated with both softness equivalent and cookie top grain, higher values were contributed by opposite parental alleles (on 1A-2, $5 \mathrm{~B}-1$, and 5DS).

The best QTL for loaf volume was at Pkabalc on 2B-1. Clark's Cream alleles resulted in higher protein, dough water absorption, and loaf volume. Clark's Cream alleles increased mixograph peak height, dough water absorption, AWRC, damaged starch, and loaf volume at the orthologous locus Pkaba1b on 2DL-1. Other important loci for loaf volume were closely linked to QTLs for flour protein quantity (Table 1, Fig. 2).

At the Glu-Dxl and Glu-Dy1 markers on 1DL, the CC alleles increased mixograph peak time and bread mixing time, dough water absorption, damaged starch, and loaf volume (Fig. 2). The association between loaf volume and markers closely linked to the Glu-D1 loci, was not great enough to be considered a QTL or in- 


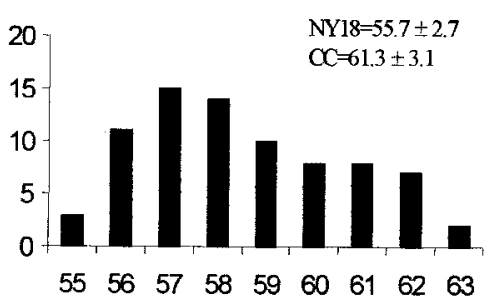

AWRC(\%)

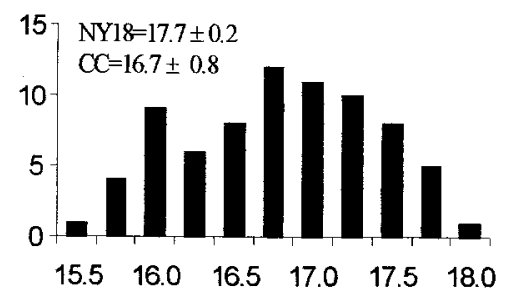

Cookie Diameter (cm)

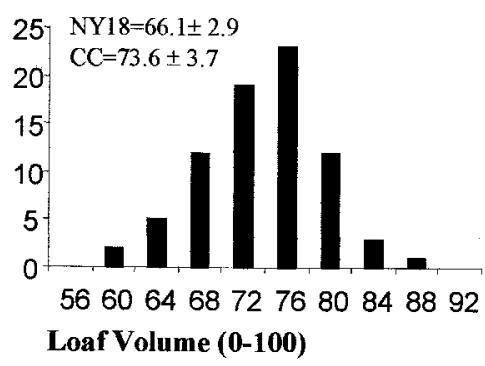

Fig. 1. Continued.

cluded in the multiple regression model (Tables 1 and 2). QTLs for loaf volume were detected on $2 \mathrm{~B}, 5 \mathrm{~L}$, and 7AL. Although CC was the considered the better bread wheat parent, the NY18 allele resulted in increased loaf volume at all the above loci except for Pkabalc.

The only two markers associated with both loaf volume and cookie diameter were Pkabalb on 2DL-1 and $b c d 1150 a$ on 1DL, but only after the model was adjusted for the effects of Pinb. In both cases, the parental alleles influenced the traits in opposite directions.

Multiple regression models for cookie traits included alleles from both parents. The CC allele at Pinb improved cookie top grain and the NY18 allele improved bread crumb grain (Fig. 2, Table 2).

\section{DISCUSSION}

This study confirmed previous research noting the importance of the glutenin loci on bread-baking quality. In this population, the Glu-D1 loci affected peak time while the $G l u-A 1$ and $G l u-B 1$ loci were associated with peak height and right of peak slope. Rousset et al. (1992) also noted that the glutenin loci on $1 \mathrm{DL}$ were more strongly associated with mixing time than those on $1 \mathrm{~B}$ or 1D. The QTLs on 1AS for flour protein and mixograph tolerance may be due to variation at gliadin or LMW glutenin genes. Nieto-Taladriz et al. (1994) reported that the Gli-B1 locus had effect on dough rheology
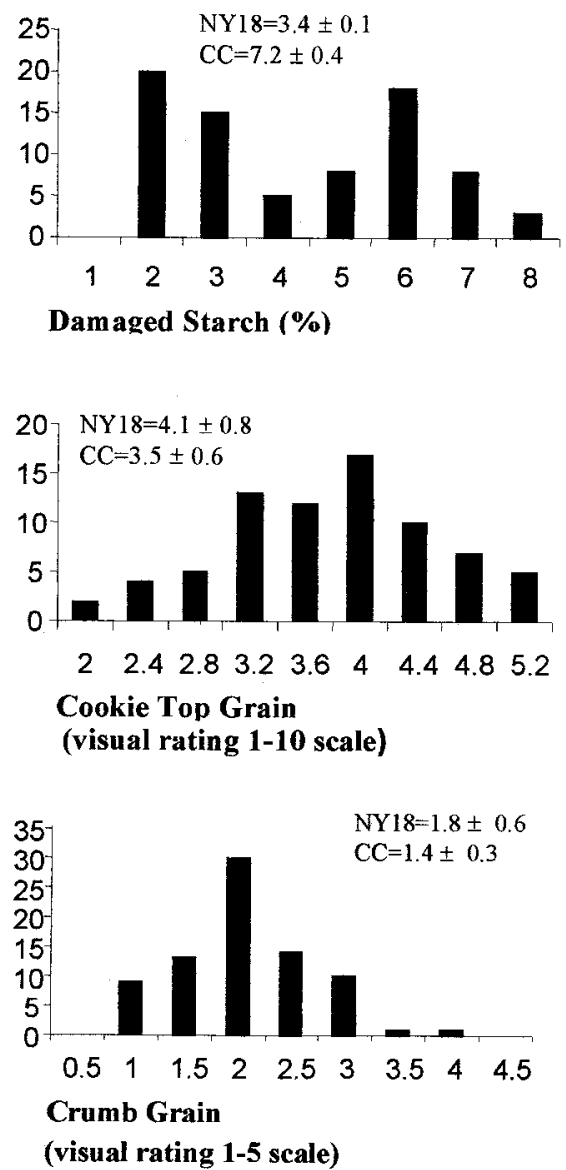

as measured with an alveograph. Payne et al. (1987) suspected that the effects of the Gli-A1 locus on dough were due to the LMW glutenin subunits at the closely linked Glu-A3. In our study, stronger gluten wheats as defined by high protein quantity, long peak time, high peak height, and long tolerance had the NY18 allele at Glu-Axl, and the CC allele at Glu-Dxl and GluDy1. At Glu-By1, opposite parents improved tolerance and peak height.

The major QTL for milling and hydration traits was located at Pinb at or near the $\mathrm{Ha}$ locus on chromosome 5DS (Giroux and Morris, 1998). Because all the samples were tempered to the same degree and milled on the same mill without adjustment, the differences between hard and soft wheat milling due to Pinb may be overemphasized. In a commercial mill, hard and soft wheat would be tempered to different moisture levels and the milling equipment would be adjusted to better suit the difference in kernel texture. Even so, by selecting for the wild-type Pinb alleles, soft wheat breeders are probably increasing softness, decreasing damaged starch, and decreasing flour yield in soft $\times$ hard wheat populations.

Protein quantity, hydration, mixograph, and loaf volume traits were influenced by loci on the two linkage groups mapping to $2 \mathrm{~B}$. Chromosome $2 \mathrm{~B}$ may contain genes that affect grain fill or affect kernel composition, rather than protein genes per se. Pkabalc, on 2B-1, is an abscisic acid responsive kinase that acts as a key 

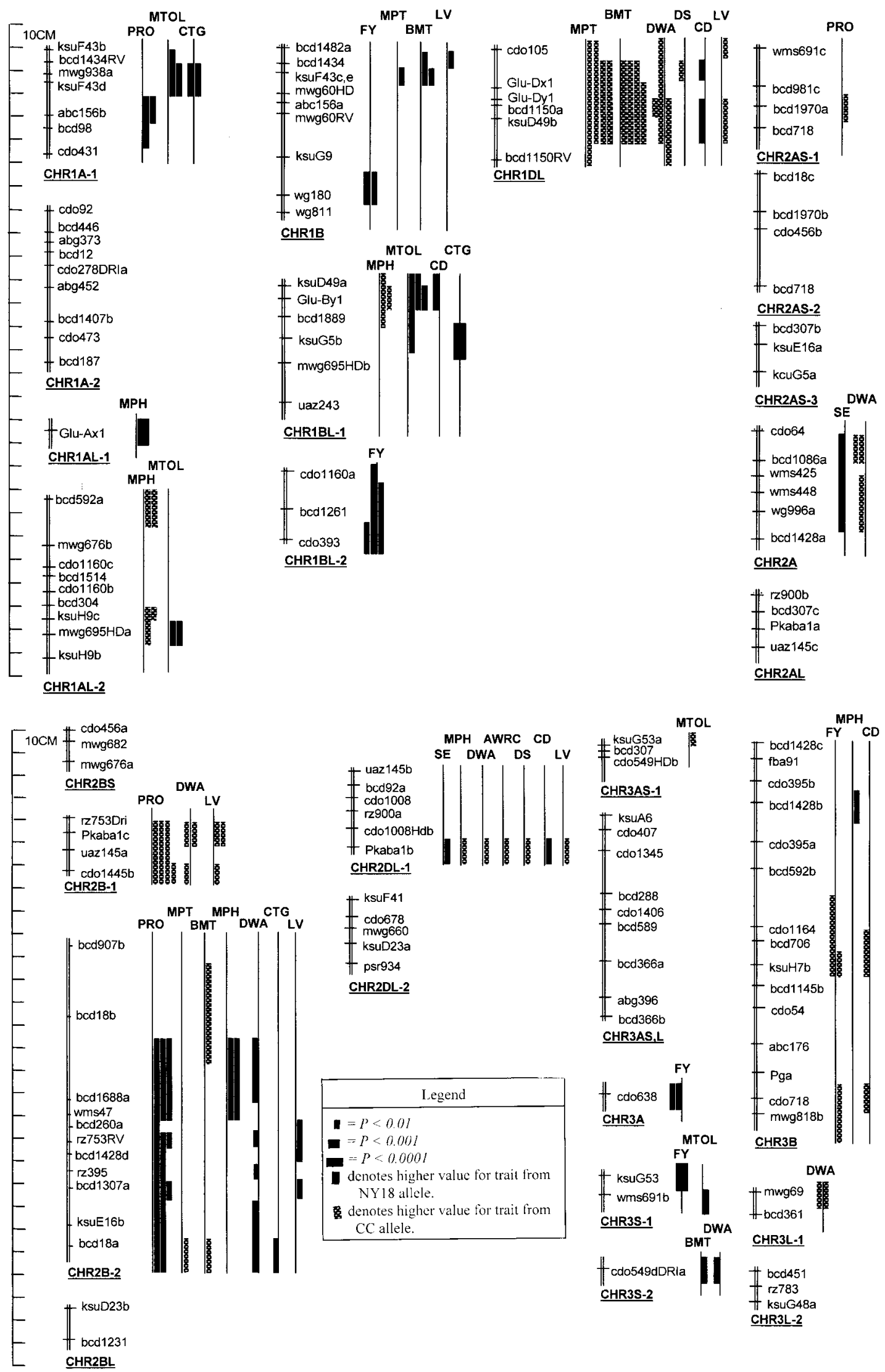

Fig. 2. The current molecular map and graphical genotypes for the NY 6432-18/Clark's Cream (NY18/CC) population. Trait abbreviations are AWRC, alkaline water retention capacity; BCG, bread crumb grain; BMT, bread mixing time; CD, cookie diameter; CTG, cookie top grain; DS, damaged starch; DWA, dough water absorption; FY, flour yield; LV, loaf volume; MPH, mixograph peak height; MPT, mixograph peak time; MTOL, mixograph tolerance; PRO, flour protein quantity; SE, softness equivalent. The width of the line used to designate a QTL denotes its significance. Lines drawn to the right were significant in single factor ANOVA. Lines drawn to the left were significant when the model included adjustment for the QTL at Pinb. 

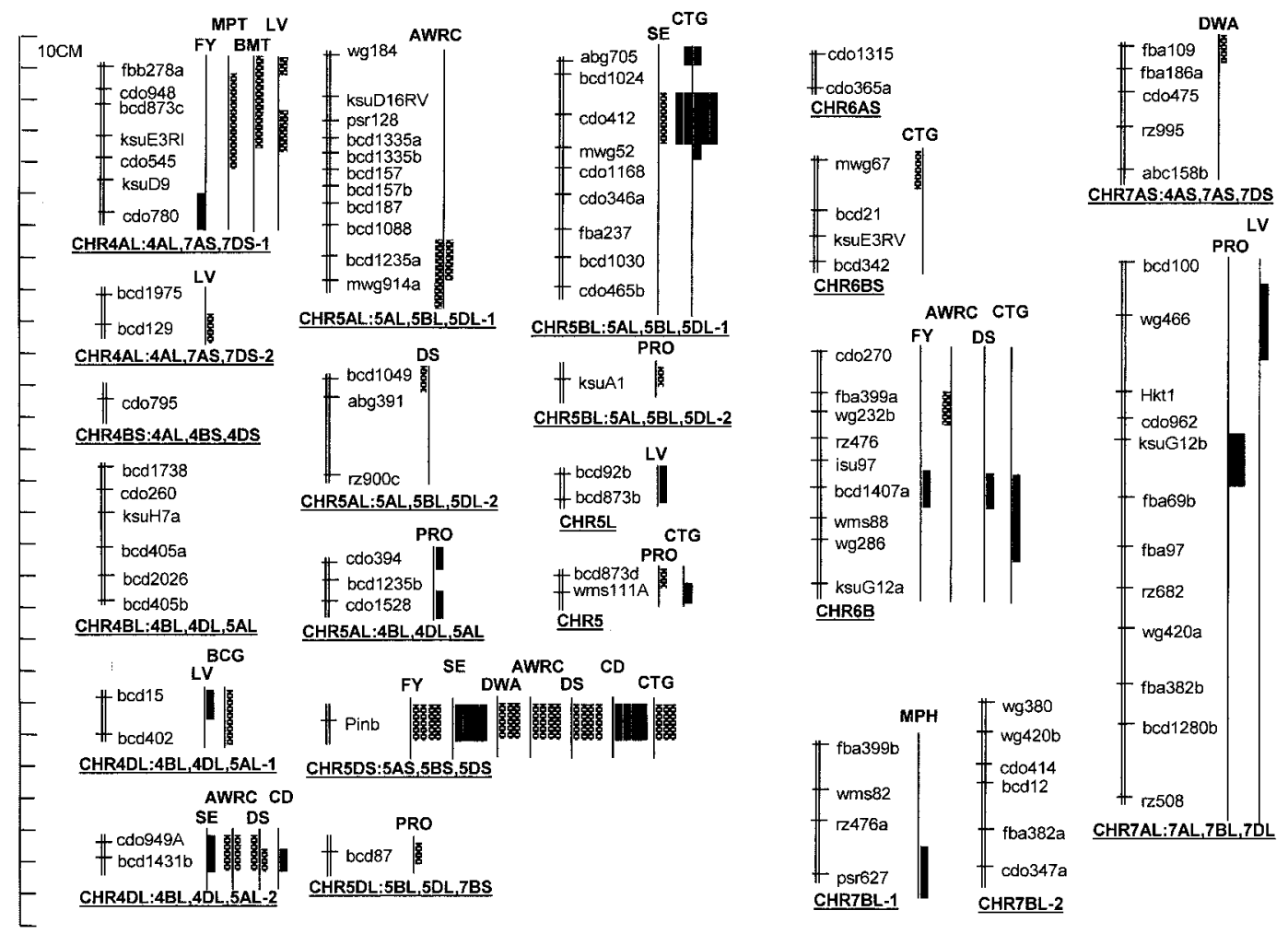

Fig. 2. Continued.

intermediate in the signal transduction pathway leading to the suppression of gibberellic acid-inducible gene expression in cereal aleurone layers (Gomez-Cadenas, 1999). Genes induced by gibberellic acid and expressed in cereal aleurone play key roles in the breakdown of endosperm during germination.

On chromosome 2B-2, QTLs for several kernel composition and size traits including starch viscosity, kernel width and test weight have also been identified at $r z 753 R V$ or $b c d 135 c$ ( $r z 753 R V$ cosegregates with several markers including bcd135c) (Campbell et al., 1999; Udall et al., 1999). For all of those traits, the NY18 allele resulted in a trait value that was the opposite of that expected on the basis of parental means. In our current study, the NY18 allele increased flour protein, peak height, and loaf volume even though NY18 had lower values for those traits than CC. The RILs are highly skewed towards NY18 in the $2 \mathrm{~B}-2$ region. At bcd1307, $80 \%$ of the progeny have the NY18 allele. Because of the skewing towards NY18, an extremely low value for protein in one or two of the RILs possessing the CC allele at this locus would bias the mean for that marker class. Closer examination of the data indicated that the reduced protein occurred in all RILs possessing the CC allele. On 2B-1, the skewing is in the opposite direction. Eighty percent of the progeny have the $\mathrm{CC}$ allele.

The CC alleles at $c d o 718$ on 3B increased flour yield and cookie diameter after the adjustment for the effects of Pinb. In our previous study, the CC allele at $c d o 718$ increased 1000- kernel weight, kernel length, area, and perimeter. A QTL for flour paste viscosity was also discovered at $c d o 718$ but only in certain environments (Campbell et al., 1999; Udall et al., 1999). Selection for the CC allele at cdo718 may result in simultaneous improvement of flour yield, kernel size, and baking quality for soft wheat.

Our results had some overlap with previous reports. The effects of the group 1 chromosomes on mixing time, loaf volume, and protein quantity have been noted above. Like Mansur et al. (1990), we observed that dough water absorption was influenced by loci on chromosome $2 \mathrm{D}$ and 3 , and loaf volume was affected by loci on 7A. Zemetra et al. (1987) reported that loci on 3B affected tolerance and we noted an effect on 3AS-1 and 3S-1. Like Prasad et al. (1999), Law et al. (1978), and Blanco et al. (1996), we also observed significant effects on flour protein on homeologous groups 2, 5, and 7.

Our population size was not large, and we experienced some difficulties in QTL identification as a result. We haven't been able to develop a complete map because we haven't sampled enough recombination events in the genome. Quantitative trait loci mapping to the skewed regions on chromosome $2 \mathrm{~B}$ need to be further explored. Because we were working with highly homozygous RILs that could be replicated, we have a high degree of confidence in our trait data and we have been able to identify several highly significant QTLs for both soft and hard wheat quality traits. These remain to be confirmed in crosses made with lines from this population as well as additional wheat populations.

In this population, the best soft wheats can be identi- 
Table 2. Multiple regression models based on molecular markers for milling and baking quality traits.

\begin{tabular}{|c|c|c|c|c|c|c|}
\hline Trait & Heritability $\dagger$ & $\begin{array}{c}\text { Adjusted } R^{2} \\
\text { for model }\end{array}$ & $\begin{array}{l}\text { Markers } \\
\text { in model }\end{array}$ & $\begin{array}{c}\text { Wheat } \\
\text { chromosome }\end{array}$ & $\begin{array}{l}\text { High parent } \\
\text { for trait }\end{array}$ & Partial $R^{2}$ \\
\hline \multicolumn{7}{|l|}{ Milling traits } \\
\hline \multirow[t]{4}{*}{ Flour yield $\uparrow$} & 0.96 & 0.70 & Pinb & 5DS:5AS,5BS,5DS§ & CC & 0.530 \\
\hline & & & cdo393 & 1BL-2 & NY18 & 0.068 \\
\hline & & & bcd706 & 3B & CC & 0.050 \\
\hline & & & ksuG53 & 3S-1 & NY18 & 0.049 \\
\hline \multirow[t]{3}{*}{ Softness equivalent } & 0.98 & 0.77 & Pinb & 5DS:5AS,5BS,5DS & NY18 & 0.658 \\
\hline & & & $k s u H 7 b$ & 3B & $\mathrm{CC}$ & 0.065 \\
\hline & & & bcd466 & 1A-2 & NY18 & 0.051 \\
\hline \multicolumn{7}{|l|}{ Protein and mixing traits } \\
\hline \multirow[t]{4}{*}{ Flour protein } & 0.90 & 0.51 & bcd1307a & 2B-2 & NY18 & 0.304 \\
\hline & & & mwg69 & 3L-1 & CC & 0.102 \\
\hline & & & cdo394 & 5AL:4BL,4DL,5AL & NY18 & 0.100 \\
\hline & & & bcd87 & 5DL:5BL,5DL,7BS & CC & 0.062 \\
\hline \multirow[t]{4}{*}{ Mixograph peak time } & 0.96 & 0.64 & Glu-Dy1 & 1DL & CC & 0.413 \\
\hline & & & bcd1434 & 1B & NY18 & 0.107 \\
\hline & & & bcd18b & 2B-2 & $\mathbf{C C}$ & 0.068 \\
\hline & & & cdo545 & 4AL:4AL,7AS,7DS-1 & $\mathbf{C C}$ & 0.050 \\
\hline \multirow[t]{4}{*}{ Bread mixing timeII } & 0.94 & 0.65 & Glu-Dy1 & 1DL & $\mathbf{C C}$ & 0.372 \\
\hline & & & bcd1434 & 1B & NY18 & 0.150 \\
\hline & & & bcd18b & 2B-2 & CC & 0.083 \\
\hline & & & cdo545 & 4AL:4AL,7AS,7DS-1 & $\mathbf{C C}$ & 0.044 \\
\hline \multirow[t]{4}{*}{ Mixograph peak height } & 0.93 & 0.56 & bcd592a & 1AL-2 & CC & 0.177 \\
\hline & & & Pkabalb & 2DL-1 & $\mathbf{C C}$ & 0.145 \\
\hline & & & bcd1307a & 2B-2 & NY18 & 0.119 \\
\hline & & & Glu-By1 & 1BL-1 & CC & 0.116 \\
\hline \multirow[t]{2}{*}{ Mixograph tolerance } & 0.65 & 0.30 & Glu-By1 & 1BL-1 & NY18 & 0.196 \\
\hline & & & $m w g 938 a$ & 1A-1 & NY18 & 0.103 \\
\hline \multicolumn{7}{|l|}{ Hydration traits } \\
\hline \multirow[t]{4}{*}{ Dough water absorption } & 0.76 & 0.53 & Pinb & 5DS:5AS,5BS,5DS & $\mathbf{C C}$ & 0.227 \\
\hline & & & bcd1150a & 1DL & $\mathbf{C C}$ & 0.144 \\
\hline & & & bcd87 & 5DL:5BL,5DL,7BS & $\mathbf{C C}$ & 0.093 \\
\hline & & & $m w g 69$ & 3L-1 & $\mathbf{C C}$ & 0.068 \\
\hline \multirow[t]{4}{*}{ Damaged starch } & 0.99 & 0.81 & Pinb & 5DS:5AS,5BS,5DS & $\mathbf{C C}$ & 0.700 \\
\hline & & & cdo949a & 4DL:4BL,4DL,5AL-2 & $\mathbf{C C}$ & 0.050 \\
\hline & & & $k s u H 7 b$ & 3B & NY18 & 0.028 \\
\hline & & & bcd446 & 1A-2 & NY18 & 0.027 \\
\hline \multirow[t]{3}{*}{ AWRC } & 0.85 & 0.52 & Pinb & 5DS:5AS,5BS,5DS & CC & 0.394 \\
\hline & & & bcd1431b & 4DL:4BL,4DL,5AL-2 & $\mathbf{C C}$ & 0.083 \\
\hline & & & bcd1235a & 5AL:5AL,5BL,5DL-1 & $\mathbf{C C}$ & 0.039 \\
\hline \multicolumn{7}{|l|}{ Baked product traits } \\
\hline \multirow[t]{2}{*}{ Cookie diameter } & 0.96 & 0.58 & Pinb & 5DS:5AS,5BS,5DS & NY18 & 0.479 \\
\hline & & & $k s u H 7 b$ & 3B & CC & 0.102 \\
\hline \multirow[t]{3}{*}{ Cookie top grain } & 0.42 & 0.41 & Pinb & 5DS:5AS,5BS,5DS & CC & 0.209 \\
\hline & & & cdo412 & 5BL:5AL,5BL,5DL-1 & NY18 & 0.107 \\
\hline & & & ksuG5b & 1BL-1 & NY18 & 0.099 \\
\hline \multirow[t]{4}{*}{ Loaf volume } & 0.79 & 0.43 & Pkabalc & 2B-1 & CC & 0.143 \\
\hline & & & fbb278a & 4AL:4AL,7AS,7DS-1 & $\mathbf{C C}$ & 0.120 \\
\hline & & & Pkabalb & 2DL-1 & $\mathbf{C C}$ & 0.097 \\
\hline & & & bcd592a & 1AL-2 & CC & 0.072 \\
\hline \multirow[t]{3}{*}{ Bread crumb grain } & 0.46 & 0.23 & $w g 180$ & 1B & NY18 & 0.073 \\
\hline & & & bcd18a & 2B-2 & NY18 & 0.069 \\
\hline & & & $w g 466$ & 7AL:7AL,7BL,7DL & NY18 & 0.060 \\
\hline
\end{tabular}

$\dagger$ Heritabilities calculated based upon genotype means. Details and further discussion are in Bergman et al. (1998).

+ The dependent variable in regression models was the genotype mean over environments for each trait.

$\S$ Markers on chromosomes 4, 5, and 7 are listed with their chromosome homologies according to Nelson et al. (1995).

II Heritabilities were calculated based upon two environments only for bread mixing time, dough water absorption, damaged starch, cookie diameter, cookie top grain, loaf volume, and crumb grain.

fied by selecting for the NY18 alleles at Pinb and ksuG53 to improve milling traits, the NY18 alleles at $b c d 1431 b$ for reduced AWRC and damaged starch, and the CC allele at $k s u H 7 b$ for improved cookie diameter. Hard wheats with a high loaf volume, protein, mixing time, and milling quality could be identified by selecting for the CC alleles at Pinb, Glu-D1, and Pkabalc, and the NY18 alleles at bcd1307a and Glu-A1.

Although the two parents differed by a small amount for several traits, we observed a significant range among the progeny. Many of the multiple regression models included alleles from both parents. Milling, cookie, and bread quality traits were all improved through interclass allelic associations. Only the hydration traits were class specific because of the strong effect of Pinb. The QTL analysis allowed us to identify specific loci that could be selected from each parent for improvement of traits in the opposite class. Hybridization among classes may be an under exploited wheat breeding strategy for quality improvement as well as agronomic improvement in wheat.

\section{ACKNOWLEDGMENTS}

We thank Lonnie Andrews, Amy Bugaj, Sharon Croskey, Barbara Gibson, Geogianna Kirchhofer, and Ron Martin at the USDA-ARS Soft Wheat Quality Laboratory for their excellent technical assistance. Thanks also to Charles Gains, Craig Morris and two anonymous reviewers for their com- 
ments and suggestions. Research supported by state and federal funds appropriated to OARDC, the Ohio Seed Improvement Association, The Mennel Milling Company, and Hatch project $149-419$ and 216.

\section{REFERENCES}

AACC. 1983. Approved methods. 8th ed. Am. Assoc. of Cereal Chem., Inc., St. Paul, MN.

Anderson, J.A., M.E. Sorrells, and S.D. Tanksely. 1993. RFLP analysis of genomic regions associated with resistance to pre-harvest sprouting in wheat. Crop Sci. 33:453-459.

Bass, E.J. 1988. Wheat flour milling. p. 1-68. In Y. Pomeranz (ed.) Wheat chemistry and technology. 3rd ed. Vol. II. Am. Assoc. of Cereal Chem, St. Paul, MN.

Bergman, C.J., D.G. Gualberto, K.G. Campbell, M.E. Sorrells, and P.L. Finney. 1998. Genotype and environment effects on wheat quality traits in a population derived from a soft by hard cross. Cereal Chem. 75:729-737.

Blanco, A., C. De Giovanni, B. Laddomada, A. Sciancalepore, R. Simeone, K.M. Devos and M.D. Gale. 1996. Quantitative trait loci influencing grain protein content in tetraploid wheats. Plant Breeding 115:310-316.

Bloksma, A.H., and W. Bushuk. 1988. Rheology and Chemistry of Dough. p. 131-218. In Y. Pomeranz (ed.) Wheat: Chemisty and technology. 3rd ed. Vol. II. Am. Assoc. of Cereal Chem., St. Paul, MN.

Brown, A.H.D., G.J. Lawrence, M. Jenkin, J. Douglass, E. Gregory. 1989. Linkage drag in backcross breeding in barley. J. Hered. 80:234-239.

Campbell, K.G., C.J. Bergman, D.G. Gualberto, J.A. Anderson, M.J. Giroux, G. Hareland, R.G. Fulcher, M.E. Sorrells, and P.L. Finney. 1999. Quantitative trait loci associated with kernel traits in a soft by hard wheat cross. Crop Sci. 39:1184-1195.

Carver, B.F. 1996. Yield and hard wheat quality attributes in hard $\mathrm{x}$ soft red winter progeny. Crop Sci. 36:433-438.

Finney, P.L., and L.C. Andrews. 1986. Revised microtesting for soft wheat quality evaluation. Cereal Chem. 63:177-182.

Giroux, M.J., and C.F. Morris. 1998. Wheat grain hardness results from highly conserved mutation in the friabilin components puroindoline a and b. Proc. Natl. Acad. Sci. USA 95:6262-6266.

Gomez-Cadenas A., S.D. Verhey, L.D. Holappa, Q. Shen, T-H.D. Ho, and M.K. Walker-Simmons. 1999. An abscisic acid-induced protein kinase, PKABA1, mediates abscisic acid-suppressed gene expression in barley aleurone layers. Proc. Natl. Acad. Sci. USA 99:1767-1772.

Hazen, S.P., P.K.W. Ng, and R.W. Ward. 1997. Variation in grain functional quality for soft winter wheat. Crop Sci. 37:1086-1093.

Hoseney, C., P. Finney, and J.W. Wade. 1988. Soft wheat products. p. 407-456. In Y. Pomeranz (ed.) Wheat chemistry and technology. 3rd ed. Vol. II. Am. Assoc. of Cereal Chemists, St. Paul, MN.

Joppa, L.R., C. Du, G.E. Hart, and G.A. Hareland. 1997. Mapping gene(s) for grain protein in tetraploid wheat (Triticum turgidum L.) using a population of recombinant inbred chromosome lines. Crop Sci. 37:1586-1589.

Khan, I.A., J.D. Procunier, D.G. Humphreys, G. Tranquilli, A.R. Schlatter, S. Marcucci-Poltri, R. Frohberg, and J. Dubcovsky. 2000 Development of PCR-based markers for a high grain protein content gene from Triticum turgidum ssp dicoccoides transferred to bread wheat. Crop Sci. 40:518-524.

Knapp, S.J., W.W. Stroup, and W.M. Ross. 1985. Exact confidence intervals for heritability on a progeny mean basis. Crop Sci. 25:192194.

Law, C.N., C.F. Young, J.W.S. Brown, J.W. Snape, and A.J. Worland. 1978. The study of grain protein control in wheat using whole chromosome substitution lines. p. 483-502. In Seed protein improvement by nuclear techniques. Ind. At. Energy Agency, Vienna, Austria.

Manly K.F., and J.M. Olson. 1999. Overview of QTL mapping software and introduction to Map Manager QT. Mamm. Genome 1:327-334.

Mansur, L.M., C.O. Qualset, D.D. Kasarda, and R. Morris. 1990. Effects of 'Cheyenne' chromosomes on milling and baking quality in 'Chinese Spring' wheat in relation to glutenin and gliadin storage proteins. Crop Sci. 30:593-602.

May, L., D.A.Van Sanford, and P.L. Finney. 1989. Soft wheat milling and baking quality in a soft red winter $\mathrm{x}$ hard red winter wheat population. Cereal Chem. 66:378-381.

Miller, R.A., R.C. Hoseney, and C.F. Morris. 1997. Effect of formula water content on the spread of sugar-snap cookies. Cereal Chem. 74:669-671.

Nietro-Taladriz, M.T., M.R. Perretant, and M. Rousset. 1994. Effect of gliadins and HMW and LMW subunits of glutenin on dough properties in the $\mathrm{F}_{6}$ recombinant inbred lines from a bread wheat cross. Theor. Appl. Genet. 88:81-88.

Nelson, J.C., M.E. Sorrells, A.E. Van Deynze, Y.H. Lu, M. Atkinson, M. Bernard, P. Leroy, J.D. Faris, and J.A. Anderson. 1995. Molecular mapping of wheat. Major genes and rearrangements in homoeologous groups 4, 5, and 7. Genetics 141:721-731

Nelson, J.C. 1997. QGENE: Software for marker based genome analysis and breeding. Molecular Breeding 229-235.

Payne, P.I., L.M. Jackson, E.A. Holt, and C.N. Law. 1984. Wheat storage proteins: their genetics and their potential for manipulation by plant breeding. Philos. Trans. R. Soc. London, Ser. B. 304:359371.

Payne, P.I., M.A. Nightingale, A.F. Krattiger, and L.M. Holt. 1987. The relationship between HMW glutenin subunit composition and the bread-making quality of British-grown wheat varieties. J. Sci. Food Agric. 40:51-65.

Prasad, M., R.K. Varshney, A. Kumar, H.S. Balyan, P.C. Sharma, K.J. Edwards, H. Singh, H.S. Dhaliwal, J.K. Roy, and P.K. Gupta. 1999. A microsatellite marker associated with a QTL for grain protein content on chromosome arm 2DL of bread wheat. Theor. Appl. Genet. 99:341-345.

Rousset, M., J.M. Carillo, C.O. Qualset, and D.D. Kasarda. 1992. Use of recombinant inbred lines of wheat for study of associations of high-molecular-weight glutenin subunit alleles to quantitative traits: 2. Milling and bread-baking quality. Theor. Appl. Genet. 83:403-412.

Schachtman, D.P., and J.I. Schroeder. 1994. Structure and transport mechanism of a high-affinity potassium uptake transporter from higher plants. Nature 370:655-658.

Shogren, M.D., and K.F. Finney. 1984. Bread-making test for 10 grams of flour. Cereal Chem. 61:418-423.

Symes, K.J. 1965. The inheritance of grain hardness in wheat as measured by the particle-size index. Aust. J. Agric. Res. 16:113-123.

Trick, M., E.S. Dennis, K.J.R. Edwards, and W.J. Peacock. 1988 Molecular analysis of the alcohol dehydrogenase gene family of barley. Plant Mol. Biol. 11:147-160.

Udall. J.A., E. Souza, J. Anderson, M.E. Sorrells, and R.S. Zemetra. 1999. Quantitative trait loci for flour viscosity in winter wheat. Crop Sci. 39:239-242.

Yamazaki, W.T. 1953. An alkaline water retention capacity test for the evaluation of cookie baking potentialities of soft winter wheat flours. Cereal Chem. 30:242-246.

Yamazaki, W.T., J.R. Donelson, and L.W. Briggle. 1968. Microtests for soft wheat quality evaluation. Crop Sci. 8:199-200.

Zemetra, R.S., R. Morris, P.J. Mattern, and L. Seip. 1987. Gene locations for flour quality in winter wheat using reciprocal chromosome substitutions. Crop Sci. 27:677-681.

Zeng Z.B. 1994. Precision mapping of quantitative trait loci. Genetics 136:1457-1466. 